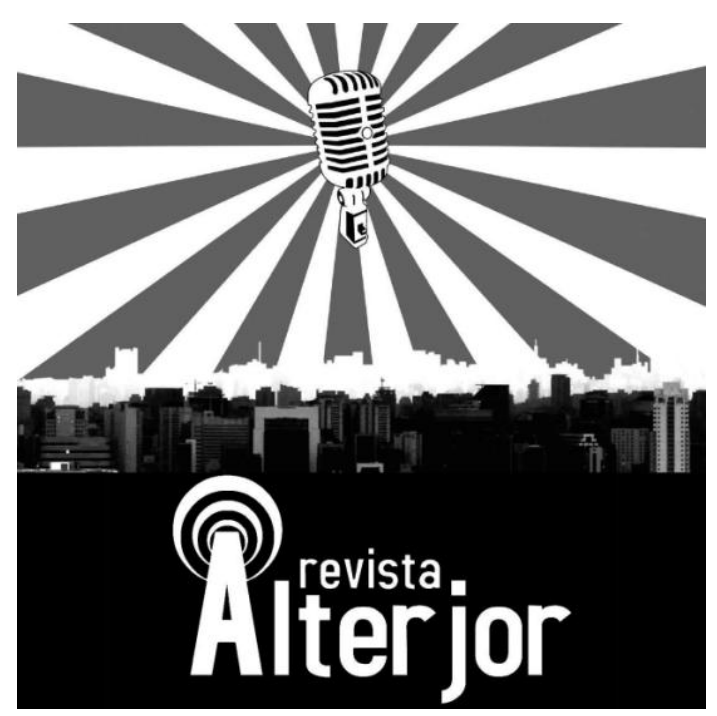

\title{
YOUTUBERS INDÍGENAS NO BRASIL: ABORDAGENS POLÍTICAS E COMUNICATIVAS
}

\author{
Rose Mara Vidal de Vidal de Souza ${ }^{1}$ \\ Mônica Panis Kaseker ${ }^{2}$
}

\begin{abstract}
RESUMO: Os povos indígenas passaram a utilizar os meios de comunicação digitais como ferramentas de afirmação de suas identidades, de resistência e de posicionamento político. Este artigo apresenta uma discussão sobre o ativismo indígena no YouTube. Do ponto de vista metodológico, o estudo tem por base a pesquisa bibliográfica e exploratória. O referencial teórico perpassa por Hall, Bauman e Eagleton sobre a questão das identidades culturais e Araújo, Di Felice e Braighi sobre os conceitos de ciberativismo, netativismo e midiativismo. Foram realizados um mapeamento da presença indígena no You Tube e uma análise dos canais dos youtubers indígenas Ysani Kalapalo e Cristian Wariu. Com posicionamentos políticos e abordagens comunicativas totalmente diversas, os dois youtubers surgem como importantes influenciadores digitais no Brasil contemporâneo.
\end{abstract}

PALAVRAS-CHAVE: Ativismo midiático. Identidade Indígena. YouTube. Youtubers.

ABSTRACT: Indigenous peoples started to use digital media as tools to affirm their identities, resistance and political positioning. This article presents a discussion of indigenous activism on YouTube. From a methodological point of view, the study is based on bibliographical and exploratory research. The theoretical framework runs through Hall, Bauman and Eagleton on the issue of cultural identities and Araújo, Di Felice and Braighi on the concepts of cyberactivism, net-activism and media activism. A mapping of the indigenous presence on You Tube and an analysis of the channels of the indigenous youtubers Ysani Kalapalo and Cristian Wariu were carried out. With totally different political positions and communicative approaches, the two youtubers emerge as important digital influencers in contemporary Brazil.

KEYWORDS: Media activism Indigenous Identity. YouTube. Youtubers.

\footnotetext{
${ }^{1}$ Pós-doutoranda no Programa de Pós-Graduação em Comunicação da Universidade Estadual de Londrina. Doutora e Mestre em Comunicação Social pela Universidade Metodista de São Paulo (Umesp). MBA em Marketing Político. Bacharel em Jornalismo. Docente Permanente do Programa de Pós-Graduação em Gestão Pública (PGGP/Ufes). Email: rosevidal@yahoo.com.br

${ }^{2}$ Doutora em Sociologia pela Universidade Federal do Paraná (UFPR), com estágio doutoral na UAM-X na Cidade do México, graduada em Comunicação Social- Jornalismo pela Pontifícia Universidade Católica do Paraná (PUCPR). Docente do Programa de Pós-Graduação em Comunicação da Universidade Estadual de Londrina (UEL). E-mail: mkaseker@gmail.com
}

Revista AL TERJOR

Grupo de Estudos Alterjor: Jornalismo Popular e Alternativo (ECA-USP)

Ano 10 Volume 02 Edição 22 Juho-Dezembro de 2020

Avenida Professor Lúcio Martins Rodriģues, 443, Cidade Universitária, São Paulo, CEP: 05508-020 


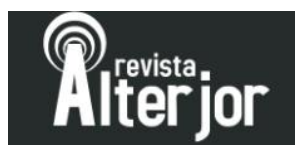

\section{Introdução}

As imagens divulgadas sobre os indígenas na mídia e mesmo nos livros didáticos reforçam e perpetuam a ideia de um indígena genérico e primitivo, como se estivesse parado no tempo desde a chegada dos europeus ao continente americano. Os povos indígenas brasileiros têm sido representados e descritos por não indígenas desde a Carta de Pero Vaz de Caminha à Coroa Portuguesa, passando pelas pinturas produzidas em expedições estrangeiras de exploração ao território, posteriormente pelas narrativas da imprensa e da literatura e, mais recentemente, pelas produções audiovisuais. No século XVI, as imagens variavam nos extremos do bom selvagem e do antropófago, dependendo dos interesses de ocasião. O olhar etnocentrista europeu, nas narrativas do século XIX, os consideravam símbolos nobres do Brasil independente quando extintos, mas "ferozes obstáculos à penetração que convinha precisamente extinguir" quando em carne e osso (CUNHA, 2009).

Falas preconceituosas fomentam o imaginário popular brasileiro de que os povos originários ao aderirem ao uso de tecnologias e costumes dos não indígenas deixam de ser "índios". A palavra "índio" possui uma forte carga simbólica que compõem a identidade indígena para a maioria da população. Para o Doutor em Educação, Daniel Munduruku, há dois conceitos no senso comum do Brasil: o olhar romântico, do "índio" que vive no meio da floresta, e o aspecto ideológico que considera que "índios são preguiçosos e atrasam o progresso". Esse imaginário, fruto do pensamento ocidental e colonizador, criou um achatamento da riqueza cultural brasileira (SEGANFREDO, 2017).

No entanto, a partir da reabertura política no Brasil, no final dos anos 1980, Canevacci (2015) considera que se iniciou uma virada epistemológica na qual os sujeitos indígenas afirmam o direito e desejo de representar a si mesmos. A partir da autorrepresentação na política e na comunicação, começa um processo de fortalecimento da identidade étnica e cultural, em uma busca por maior visibilidade do movimento indígena em meio à globalização.

No último Censo brasileiro $(2010)^{3}$, foram registrados 896,9 mil indígenas, 36,2\% em área urbana e $63,8 \%$ na área rural. O total inclui os 817,9 mil indígenas declarados no quesito cor ou raça e também as 78,9 mil pessoas que residiam em terras indígenas e se declararam de

\footnotetext{
${ }^{3}$ Disponível em https://censo2010.ibge.gov.br/noticias-censo?busca=1\&id=3\&idnoticia=2194\&t=censo2010-poblacao-indigena-896-9-mil-tem-305-etnias-fala-274\&view=noticia. Acesso em 08 de jan de 2020.
} 
outra cor ou raça (principalmente pardos, 67,5\%), mas se consideravam "indígenas" de acordo com aspectos como tradições, costumes, cultura e antepassados.

Este trabalho está inserido na pesquisa de pós-doutorado desenvolvida no Programa de Pós-Graduação em Comunicação da Universidade Estadual de Londrina (UEL). Nesta experiência, buscamos o entendimento de como se dá o midiativismo indígena no YouTube, assim como suas implicações identitárias e políticas.

A discussão teórica aborda a questão das identidades culturais, com base em autores como Stuart Hall, Bauman e Eagleton. Discute-se também os conceitos de ciberativismo, netativismo e midiativismo, a partir de autores como Araújo, Di Felice e Braighi. A pesquisa empírica consistiu na realização de um mapeamento da presença indígena no YouTube e na análise de conteúdo e linguagem dos canais selecionados na amostra.

Nesta investigação destacamos dois perfis no Youtube. A escolha se deu pelo maior número de seguidores. Ysani Kalapalo, oriunda do Parque Indígena do Xingu (MT), Ysani possui o maior canal indígena do YouTube, com 372 mil inscritos. Seus vídeos abordam questões culturais, além de compartilhar suas primeiras experiências no meio urbano. $\mathrm{O}$ segundo e terceiro perfís com mais seguidores são de duas irmãs de Ysani e seguem o mesmo formato de vídeos. Para buscar uma voz diferente no discurso indígena optamos nesta pesquisa pelo quarto lugar no ranking dos Youtubers indígenas. Neste caso ocupado pelo jovem Xavante, com ascendência Guarani, Cristian Wariu Tseremey'wa. Com pouco mais de 19 mil seguidores, o canal Wariu desconstrói a visão de senso comum dos brasileiros sobre os povos indígenas através de vídeos explicativos.

\section{Identidade e imagem}

A relação entre as representações midiáticas dos indígenas e sua própria identidade cultural, cada vez mais atravessada por hibridizações, torna-se uma discussão premente. Essas representações, ao considerarmos o período histórico pós-colonização, afetam sua percepção pelo outro, o que implica pensarmos a relação entre a identidade e a alteridade. Para Rojas Mix, a identidade cultural se relaciona ao conhecimento e à familiaridade, o que se obtém pela interação entre o contexto social e cultural em cada lugar, grupo ou setor social em dado momento de sua história. "Há uma parte importante do equipamento mental com que o homem ordena sua experiência visual, que é variável e depende em grande medida de sua familiaridade 
cultural" (MIX, 2006, p. 119). A alteridade, a imagem do outro, pode ser vista através de distintos imaginários e o etnocentrismo é uma dessas lentes que pode levar à coisificação ou demonização daquele que é diferente.

Para Bauman, a identidade está relacionada ao sentido de pertencimento. Nenhum desses aspectos é fixo ou sólido, pelo contrário são negociáveis e revogáveis. (2005, p. 17-18). Nesse sentido, dependem das decisões que "o próprio indivíduo toma, os caminhos que percorre, a maneira como age - e a determinação de se manter firme a tudo isso". A identidade não é algo a ser revelado, mas sim inventado. Segundo o autor, "as 'identidades' flutuam no ar, algumas de nossa própria escolha, mas outras infladas e lançadas pelas pessoas em nossa volta, e é preciso estar em alerta constante para defender as primeiras em relação às últimas" (BAUMAN, 2005, p. 19).

A identidade se configura ao longo do tempo, de forma inconsciente, e está em permanente transformação e expansão. Hall (1997) examina três possíveis consequências a respeito dos efeitos da globalização sobre as identidades culturais: as identidades nacionais estão se desintegrando por causa da homogeneização cultural crescente e do "pós-modernismo global"; as identidades nacionais e outras locais ou particularistas estão sendo reforçadas pela "resistência à globalização"; e as identidades nacionais estão em declínio, dando lugar às identidades híbridas. Quanto maior a exposição das culturas nacionais às influências externas, torna-se mais difícil conservar identidades culturais ou impedir seu enfraquecimento por meio do "bombardeamento ou infiltração cultural" (HALL, 1997, p. 69). Há ainda o risco de um apagamento das identidades nacionais, sob a força do desenvolvimento das identidades globais. Ao analisar esse contexto na pós-modernidade, Eagleton (2005) enfatiza a fragilização cultural e a complexidade das políticas de identidade, que vão além daquelas produzidas anteriormente pelo Estado-Nação, relacionadas ao pós-colonialismo.

As formas mais inspiradoras são aquelas em que você reivindica uma igualdade com os outros no que diz respeito a ser livre para determinar o que é que você deseja se tornar. Qualquer afirmação autêntica de diferença tem, portanto, uma dimensão universal (EAGLETON, 2005, p. 99).

Diante do exposto, segue o questionamento: Será que a presença indígena na internet pode fortalecer suas identidades étnicas e atuar no combate aos estereótipos e preconceitos? 


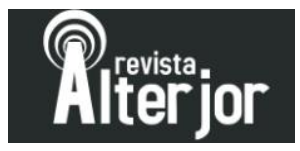

Um dos grandes braços na visibilidade da identidade indígena é o net-ativismo. A seguir abordaremos a relação deste conjunto de prática e as causas indígenas.

\section{Net-ativismo e a emergência da causa indígena}

Com o advento da popularização da Internet, especialmente a partir do acesso por dados móveis, as minorias (como indígenas, quilombolas, etc.) que antes eram excluídas das pautas dos meios de comunicação de massa passaram a buscar espaço no mundo digital. Para problematizar a emergência da causa indígena na Internet, em especial no YouTube, torna-se necessário inicialmente esclarecer alguns termos que vem sendo utilizados para se referir a essa participação.

Di Felice utiliza o termo net-ativismo, com enfoque especial para a interação dessas participações, observando uma ecologia comunicativa ampliada, com novas e mais complexas conexões. Para o autor, a primeira fase do net-ativismo foi marcada pelo compartilhamento de textos e pela passagem da mídia alternativa para a mídia participativa na Internet, ainda bastante centrada na figura de líderes e com um modelo comunicativo unidirecional de um para muitos. Numa segunda etapa, sempre acompanhando as mudanças tecnológicas da própria Internet e das plataformas digitais, surgem novos tipos de conflitos e participação descentralizados, com a participação de pessoas e movimentos. A partir da terceira fase, com a Internet 2.0 e das redes sociais, começa uma maior "interação colaborativa entre pessoas, dispositivos de conexão, bancos de dados e territorialidades" (DI FELICE, 2017, p.135).

Outro termo utilizado para se referir ao ativismo no ciberespaço é o ciberativismo, definido por Silveira como "um conjunto de práticas em defesa de causas políticas, socioambientais, sociotecnológicas e culturais, realizadas nas redes cibernéticas, principalmente na Internet” (2010, p.30). Neste sentido, para o autor, o ciberativismo se confunde com a própria expansão da rede mundial de computadores.

De acordo com Bringel e Muñoz (2010), uma das primeiras manifestações utilizando as novas tecnologias foram as revoltas zapatistas em 1994, no sul do México, que representaram uma verdadeira "revolução das revoluções", por terem sido inspiração para uma nova forma de resistência em que a comunicação digital ocupa um papel central. Em 2011, outro evento contribuiu de forma significativa para a compreensão do ciberativismo: a primavera árabe. $\mathrm{O}$ uso das redes sociais contribuiu para a queda dos ditadores na Tunísia e no Egito. Outras 
ocupações e revoltas surgiram em vários países da Europa e América, como o Occupy Wall Street nos Estados Unidos (ARAÚJO; FREITAS, 2012).

Considerando esses episódios como fundadores do chamado ciberativismo, Ugarte (2008) e Vegh (2003) relacionam este fenômeno à ação hacker ou à difusão de informações e reivindicações de forma direta, sem intermediários, para conseguir mobilizar indivíduos para ações.

Além disso o ciberativismo inclui duas palavras de ordem: poder e comunicação. Os meios de comunicação não detêm o poder, mas configuram espaços para decidir o poder. "Ao longo da história a comunicação e a informação têm constituído fontes fundamentais de poder e contrapoder a dominação e troca social" (CASTELLS, 2009, p.36). Neste contexto, surge um conceito ainda mais focado nas ações ativistas relacionadas à comunicação: o midiativismo.

Midiativismo só se faz com midiativistas, sujeitos portadores de uma vontade solidária, que empreendem ações diretas transgressivas e intencionais, e veem as próprias capacidades de intervenção social, antes localizadas, sendo potencializadas. Isso, por meio de um registro midiático que visa necessariamente amplificar conhecimento, espraiar informação, marcar presença, empreender resistência e estabelecer estruturas de defesa. (BRAIGHI; CÂMARA, 2018)

Em junho de 2013, ocorreu no Brasil uma série de manifestações, que levaram milhares de pessoas às ruas de cidades brasileiras pedindo redução no valor das passagens de ônibus. Braighi destaca que "os atos foram marcados pelo grito da crise de representatividade, política e midiática; assim, bandeiras parlamentares e logos de mídias corporativas eram pouco aceitos nas marchas.” (2018, p.43) Na ocasião, o coletivo de comunicação independente Mídia Ninja registrou os protestos ao vivo, pela Internet, pautando, inclusive, os veículos de comunicação tradicionais.

No que se refere ao movimento indígena, o midiativismo se expressa com o surgimento das etnomídias. Como no caso da rádio Yandê ${ }^{4}$, que foi fundada em novembro de 2013 por Anápuáka Tupinambá, Renata Tupinambá e Denilson Baniwa e que funciona de forma colaborativa com as comunidades indígenas de todo o país.

\footnotetext{
${ }^{4}$ Disponível em https://radioyande.com/

Revista ALTERJOR

Grupo de Estudos Alterjor: Jornalismo Popular e Alternativo (ECA-USP)

Ano 10 Volume 02 Edição $22 \quad$ Juho- Dezembro de 2020

Avenida Professor Lúcio Martins Rodrig̉ues, 443, Cidade Universitária, São Paulo, CEP: 05508-020
} 


\section{Ritieior}

Atualmente, a Yandê tornou-se um Grupo de Comunicação, que atua com a articulação dos movimentos indígenas e publicações de materiais em diversos suportes e linguagens.

\section{A presença indígena no YouTube}

No Brasil, segundo o relatório anual (2019) da WeAreSocial ${ }^{5}$, 95\% dos usuários de Internet acessam o YouTube, o que equivale a 133 milhões de pessoas. Em 2019 a plataforma de vídeos ultrapassou o Facebook com seus significativos 130 milhões de perfis. Atualmente a cada minuto, 400 horas de vídeo são enviadas para o YouTube. Ainda de acordo com o estudo, $80 \%$ das pessoas buscam nos vídeos online um conteúdo inexistente na TV a cabo. Esses números demonstram a força da rede social.

O nome YouTube ${ }^{6}$ deriva da junção das palavras you e tube, que, em inglês, significa televisão, portanto, "você na TV". Criada em 2005 por Chad Hurley, Steven Chen e Jawed Karim, quando os três trabalhavam no PayPal. Dois meses depois, a startup que crescia rapidamente foi adquirida $\mathrm{p}$

elo Google, por US\$1,65 bilhão.

De acordo Burgess e Green (2009), o slogan do Youtube era Your Digital Video Repository (“Seu Repositório de Vídeos Digitais”) e posteriormente foi substituído por Broadcast yourself ("Transmita-se a si mesmo"). Essa outra proposta do slogan representa o momento de mudança apresentado pela era digital, onde "qualquer um pode criar um vídeo, inclusive você", a liberdade do tipo de conteúdo postado é uma premissa que só é viável na Internet.

Burgess e Green (2009) ainda citam a apropriação de conteúdos da mídia analógica - seja para editar e disponibilizar partes específicas de programas de TV ou para criar conteúdo novo a partir delas - como uma grande parte do que é feito no

\footnotetext{
${ }^{5}$ Global Digital 2019. Disponível em <https://wearesocial.com/global-digital-report-2019>. Acesso em 06 de abr. de 2020.

${ }^{6} \mathrm{O}$ YouTube possibilita que qualquer usuário poste vídeos publicamente, tendo uma política de boas práticas que retira vídeos e pune aqueles que compartilham conteúdo de ódio, pornografia ou contra a lei, fora isso, qualquer pessoa pode filmar e postar o mais variado tipo de conteúdo.
} 


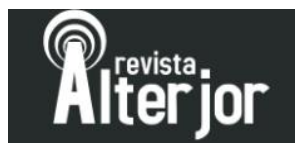

YouTube. Esse alto nível de interatividade entre os usuários, a interface e as instâncias da mídia, juntamente com o deslocamento de papéis tradicionais de consumidores passivos de informação para consumidores que ressignificam as mensagens e criam conteúdo original, definem o YouTube como um site de cultura participativa (BURGESS; GREEN, 2009, p. 17).

O acesso dos usuários para utilizar o YouTube se dá por meio de contas, que qualquer pessoa pode criar e ter acesso ou produzir conteúdo para a plataforma. O formato de apresentação é de vídeos curtos (entre 2 a 5 minutos) que podem ou não ser apresentados por uma ou duas pessoas. Aqueles indivíduos que se dedicam integralmente e obtém renda por meio da produção de conteúdo são nomeados Youtubers. Quando atingem um grande sucesso passam a ser influenciadores digitais ${ }^{7}$.

No Brasil, o maior influenciador do momento é Whindersson Nunes, um comediante com 39,1 milhões de inscritos. Os que fazem mais sucesso são os canais relacionados a entretenimento. O YouTube criou inclusive placas para os criadores de conteúdo que possuem maior número de inscritos. São elas: Prêmio Prata para Criadores -100 mil inscritos; Prêmio Ouro para Criadores - 1 milhão de inscritos; Prêmio Diamante para Criadores - 10 milhões de inscritos.

No caso do midiativismo, o alcance nem sempre é tão massificado, já que a comunicação é direcionada a públicos mais específicos e segmentados. Entre estes, estão os Youtubers Indígenas Brasileiros. Ao todo foram catalogados neste recorte da pesquisa 13 indígenas que tem canais no YouTube. Conforme infográfico na página a seguir podemos visualizar a linha do tempo detalhando cada um deles. Vale ressaltar que os indígenas iniciaram suas postagens em 2008, porém não possuem um número significativo de seguidores, o que pode indicar que ainda são incipientes em termos de divulgação, mas também, como comentado anteriormente, se dirigem a um público específico e segmentado.

\footnotetext{
${ }^{7}$ São pessoas que têm a capacidade de influenciar outras pessoas a tomarem decisões, seja estilo de vida ou consumo nas redes sociais. Podem trabalhar com nichos muito específicos, como meditação ou educação em libras, até assuntos mais gerais como viagens ou saúde.
} 


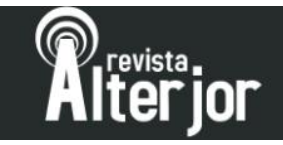

Dos Youtubers pesquisados apenas dois conseguiram, até o fechamento dessa pesquisa, atingir os 100 mil seguidores: Ysani Kalapalo com 386 mil seguidores e Diamantha Aweti Kalapalo, com 225 mil seguidores. As duas são irmãs e postam conteúdo voltados a cultura Kalapalo $^{8}$, posts pessoais e política com orientação política conservadora.

$\mathrm{Na}$ terceira posição do ranking com 26,2 mil inscrições, está a outra irmã da família do Alto Xingu, Kapaí Kalapalo. A quarta posição é do indígena Xavante Cristian Wariu Tseremey'wa, com 19,5 mil seguidores. Na quinta posição We'e'ena Tikuna, com 17,8 mil inscritos. Os oito Youturbers indígenas restantes possuem menos de 10 mil seguidores, juntos eles somam 10.243 inscritos.

Infográfico 1: Linha do tempo Youturbers indígenas brasileiros

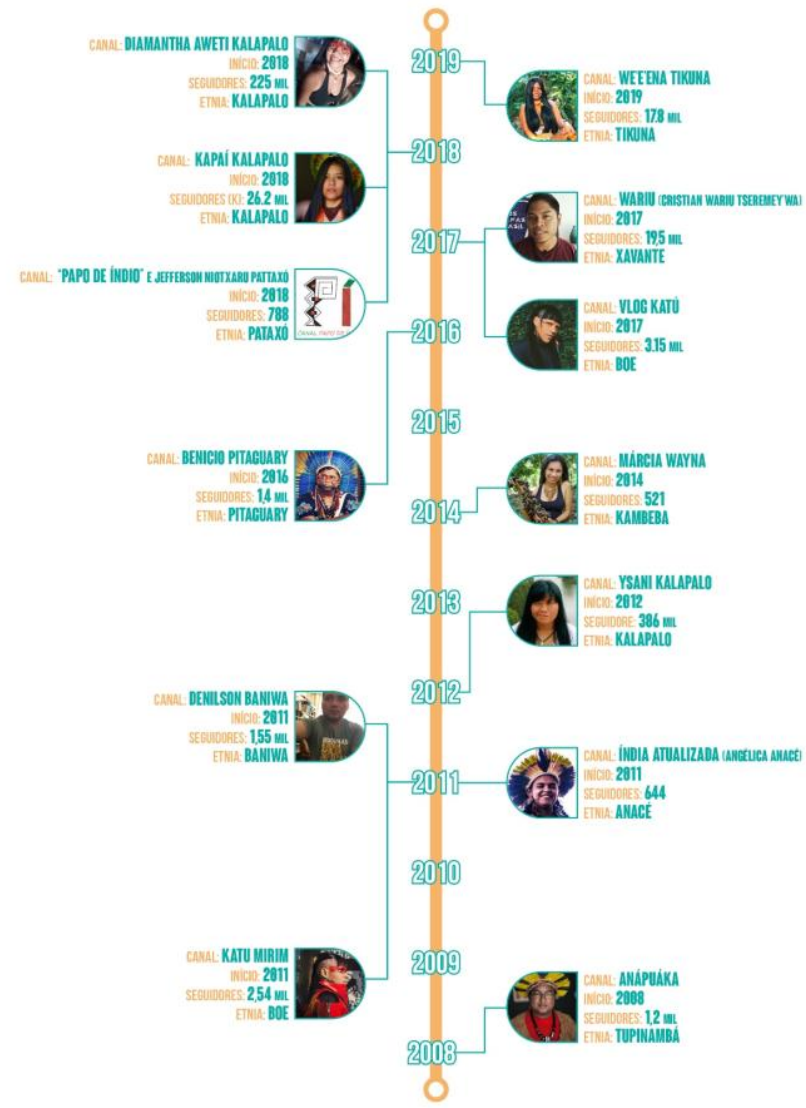

Fonte: Produzido por Rose Vidal e Ricardo Coffler.

\footnotetext{
${ }^{8}$ Kalapalo - um dos quatro grupos de língua Karib que habita a região do Alto Xingu, englobada pelo Parque Indígena do Xingu.
}

Revista ALTERJOR

Grupo de Estudos Alterjor: Jornalismo Popular e Alternativo (ECA-USP)

Ano 10 Volume 02 Edição $22 \quad$ Juho- Dezembro de 2020

Avenida Professor Lúcio Martins Rodrig̉ues, 443, Cidade Universitária, São Paulo, CEP: 05508-020 


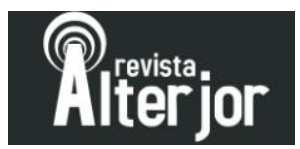

$\mathrm{Na}$ análise dos canais de Ysani Kalapalo e Cristian Wariu Tseremey'wa, foram considerados todos os vídeos postados até o dia 30 de março de 2020. Em seguida, foram classificados por ano, pela quantidade de vídeos postados, assunto (pessoal, cultural e político), visualizações e quantidade de comentários. Apurou-se que em 2019 e 2020 houve um crescimento de postagens em ambos os canais, então optou-se pelo detalhamento destes anos. Foram elaboradas tabelas com a classificação mensal do material postado e a seguir foi subdividido por subtema: Cultura (Cultura Indígena, Kalapalo/Povos do Alto Xingu e Excêntrico) e Política (Partidário, Genêro Social e Direitos Indígenas). Ao todo foram produzidas 14 tabelas e 14 gráficos $^{9}$ em um corpus de 367 vídeos distribuídos entre 2012 a 2020.

Ysani Kalapalo Ysani nasceu na aldeia Tehuhungu no parque do Xingu (MT), porém desde os 12 anos vive em São Paulo. Na cultura indigena não contam a idade nem comemoram aniversário, porém Ysani calcula ter 28 anos. Ela se autodefine como "a indígena do século 21 " e usa o canal no YouTube para falar sobre "a curiosidade indígena e outras coisas que os ouvintes pedem". Seu canal é o com maior número de seguidores entre os yoututbers indígenas, com 396 mil inscritos ${ }^{10}$.

Kalapalo iniciou as transmissões em abril de 2012, os vídeos iniciais era sobre o dia-a-dia nas aldeias como podemos observar no seu $1^{\circ}$ vídeo ${ }^{11}$, cuja descrição é a seguinte: "Povo Kuikuro do Xingu, em São Paulo vieram passar o mês do índio e mostrar seus costumes para não indígenas. Toca da Raposa-Juquitiba. Ano: 2012”. Perpassando por postagens pessoais como "Índia Ysani bagunçando os cabelos"12. Porém ao longo dos anos o canal foi se politizando.

Em publicação feita em 2018, antecedendo sua viagem a Nova York, Ysani falou de Raoni. "Tem um certo cacique que a gente vê muito na mídia. Um certo cacique que se diz representante de todos os povos do Xingu. O que não é verdade”,

\footnotetext{
${ }^{9}$ Todas as tabelas, gráficos e infográficos estão no apêndice da pesquisa original.

${ }^{10}$ Disponível em https://www.youtube.com/user/YsaniTV. Acesso em 27 de março de 2020.

${ }^{11}$ Disponível em https://www.youtube.com/watch?v=NY9vFYVMsKA.

${ }^{12}$ Disponível em https://www.youtube.com/watch?v=3XOy5QeENRE.
} 


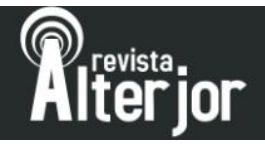

afirmou. "O cacique Raoni é cacique da aldeia dele. Ele fica lá no baixo Xingu, não no alto Xingu, não é legal você falar por todo o Xingu”, disse a Ysani.

Dos 343 vídeos postados por Ysani, 139 são de cunho cultural, 116 político e 88 pessoal. Conforme podemos observar no gráfico abaixo:

Gráfico 1: Conteúdos postados no YouTuber por Ysani Kalapalo

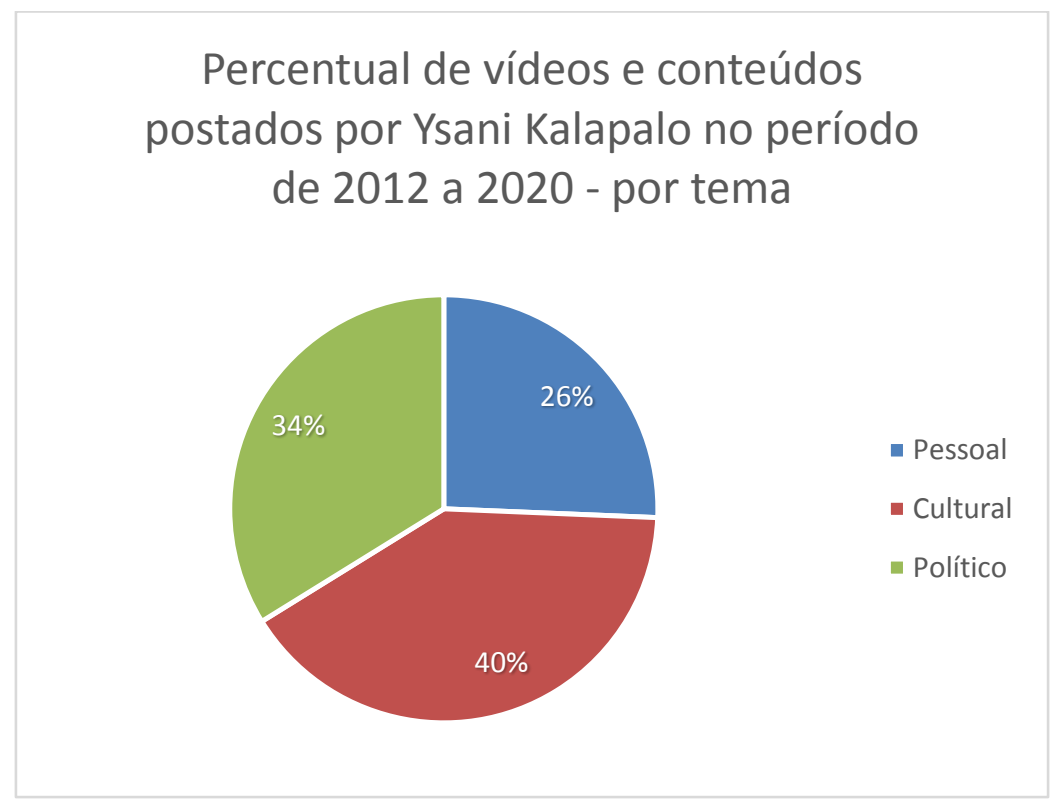

Fonte: Produzido por Rose Vidal e Ricardo Coffler

Em relação aos conteúdos postados desde sua criação, em 2012, até março de 2020, podemos observar que em 2018 houve um aumento significativo no número de vídeos postados, saltou de 7 em 2017 para 45 em 2018, um incremento de mais de 642,8\%. Em 2019 esse número saltou para 189, ou seja, 420\%, em relação a 2018 que era 45 vídeos (vide gráfico 2 e 3 ). 


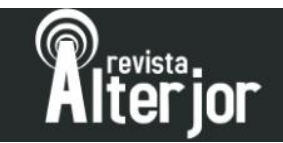

Gráfico 2: Evolução de postagens no YouTuber por Ysani Kalapalo

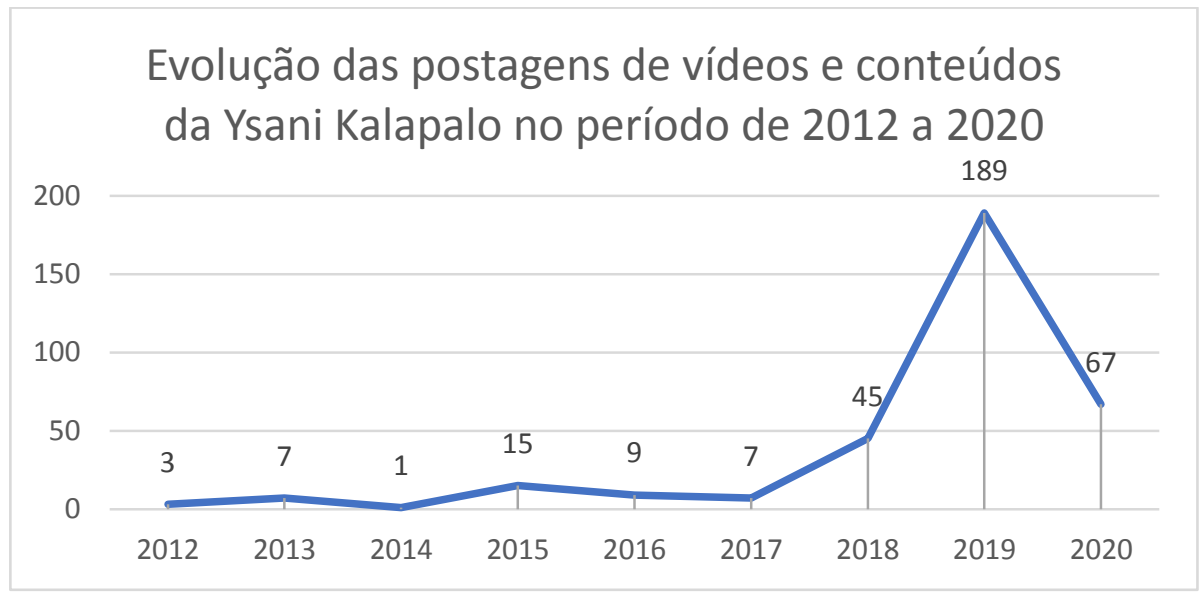

Fonte: Produzido por Rose Vidal e Ricardo Coffler

Somente nos três primeiros meses de 2020 o número de vídeos alcançaram a marca de 67. Observa-se que apesar de ter iniciado no YouTube em 2012, sua periodicidade de conteúdo só foi acontecer em 2018, coincidentemente em ano eleitoral para presidência da República no Brasil.

Corroborando essas afirmações, ainda de acordo com o gráfico 3, percebe-se o pico de produção de conteúdo em 2018 com temas abordando política. Ysani declara-se abertamente em vários vídeos que é de direita, conservadora e eleitora de Bolsonaro, dos 116 vídeos postados sobre política, 68 são de cunho partidário ${ }^{13}$. No vídeo intitulado "Por que sou indígena de direita", de 21 de maio de 2019, Ysani explica sua visão partidária. O post obteve 49.383 visualizações e 1.146 cometários. A repercussão foi tão grande que ela fez a parte II no dia 23 de maio de 2019.

Ysani dedica 35 vídeos para falar sobre direitos indígenas, sempre em primeira pessoa, raramente traz um entrevistado ou uma liderança. Quando o faz, o entrevistado corrobora suas ideias políticas. Em 2019 o discurso partidário foi enaltecido dos 75 vídeos publicados, 52 citavam direto ou indiretamente o governo de Jair Bolsonaro. Conforme o gráfico abaixo:

\footnotetext{
${ }^{13}$ Todas as tabelas, gráficos e infográficos estão no apêndice da pesquisa original. 


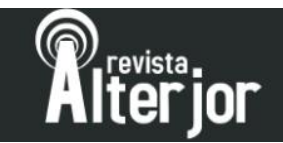

Gráfico 3: Evolução de postagens no YouTuber por Ysani Kalapalo

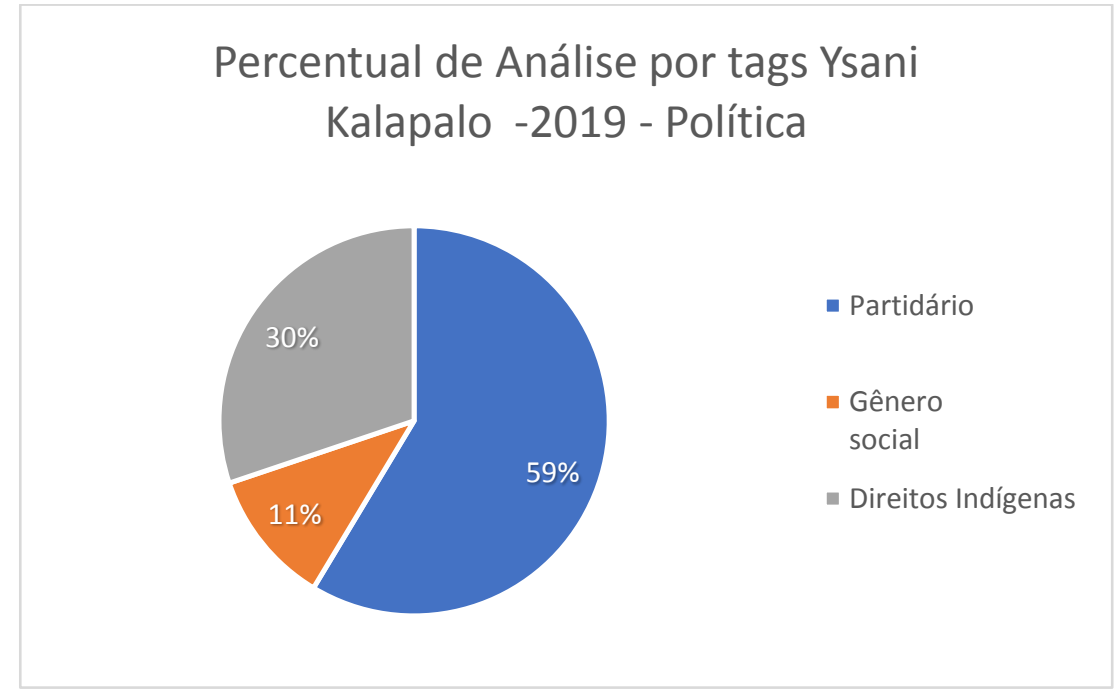

Fonte: Produzido por Rose Vidal e Ricardo Coffler

O material com cunho cultural equivale a $40 \%$ do material postado, ou seja, 139 vídeos (vide gráfico 1). Ysani Kalapalo dá destaque para sua etnia e para os povos do Alto Xingu ${ }^{14}$. Conforme o gráfico 4, são 89 vídeos narrando cotidiano indígena, como cerimônias, curiosidades, gastronomia, música, etc. Os vídeos são relacionados com respostas das perguntas feitas diretamente nos comentários dos vídeos. O vídeo “Jamugikumalu- Aldeia Tehuhungu 2017”, de 16 de outubro de 2017, possui o número record do canal de visualizações: 6.625.442, porém os comentários estão desativados. Jamurikumalu é uma cerimônia realizada pelas mulheres indígenas do Alto Xingu. Com 4 minutos de duração o vídeo foi filmado na vertical com smartphone e mostra parte da cerimônia na Aldeia Tehuhungu.

\footnotetext{
${ }^{14} \mathrm{O}$ Parque Indígena do Xingu engloba, em sua porção sul, a área cultural conhecida como alto Xingu, formada pelos povos Aweti, Kalapalo, Kamaiurá, Kuikuro, Matipu, Mehinako, Nahukuá, Naruvotu, Trumai, Wauja e Yawalapiti. Disponível em <https://pib.socioambiental.org/pt/Povo:Xingu>.
} 


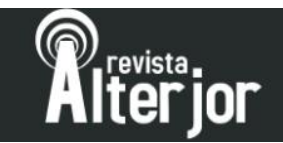

Gráfico 4: Conteúdo por tema por Ysani Kalapalo - Cultura

\section{Percentual Análise por tags Ysani Kalapalo}

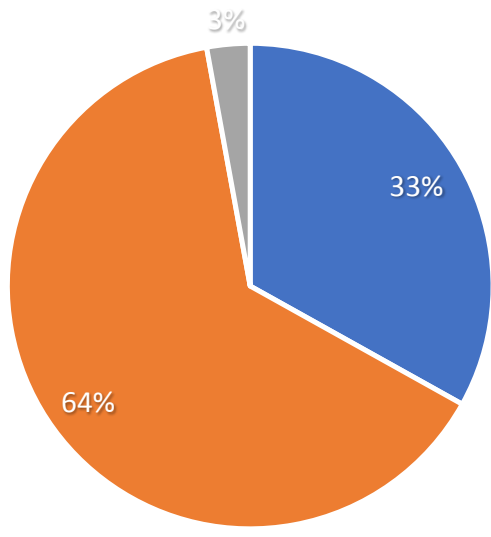

- Cultura Indígena

- Kalapalo

Povos do alto Xingu

- Excêntrico

Fonte: Produzido por Rose Vidal e Ricardo Coffler

A Youtuber Kalapalo dedica 47 postagens à cultura indígena em geral. Os vídeos abordam a colonização do Brasil, canibalismo, filmes nacionais e internacionais (sobre a cultura dos povos originários) e o que é ser índio no século XXI. Os vídeos com a temática canibal geram muito engajamento, inclusive Ysani postou um vídeo contando que seu avô era canibal, gerando 130 mil visualizações e 1.281 mil cometários.

Kalapalo dedica 88 publicações a temas excêntricos e polêmicos, como o vídeo intitulado "Por que a Pepeka das Índias do Xingu é fechada?", de 15 de maio de 2019, com 1.825.328 visualizações e 4.788 comentários. É um dos vídeos que possui mais visualizações. O sucesso foi tanto que na sequencia ela postou outro conteúdo seguindo a mesma linha. O vídeo postado em 16 de maio de 2019 "Qual o tamanho normal do Pikachu dos Índios?” possui 1.103.839 visualizações e 3110 mil comentários.

De acordo com os dados da pesquisa verificou-se que a YouTuber faz midiativismo de forma expontânea, amadora e sem muito recursos. Ysani tem um forte sotaque e por vezes fala o Português errado. Percebe-se que o argumento da cultura indígena dos Povos do Xingu e Kalapalo apresentado pela Youtuber é considerado válido pela maioria dos seus seguidores, ao todo são 38.617 .010 milhões de 


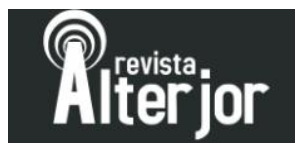

visualizações e 130.882 mil comentários. Assim como seu posicionamento político, que ocupa $34 \%$ das suas postagens, o que equivale a 116 vídeos.

O segundo perfil com mais seguidores é do jovem Xavante, com ascendência Guarani, Cristian Wariu Tseremey'wa, isto porque o pai de Cristian pertence à etnia Xavante, enquanto a mãe é Guarani. Em entrevista ao site Amazonia - Notícia Informação ${ }^{15}$, o Youtuber se considera, culturalmente, apenas ligado aos ancestrais paternos. "Conforme a linhagem dos Xavantes, o filho deve ser considerado apenas da etnia deles, independente do parceiro. Além disso, quando você precisa se identificar como indígena, como na matrícula em uma universidade, precisa mencionar apenas um povo", explica ${ }^{16}$.

Wariu nasceu em Campinápolis (MT), onde passou grande parte da infância e da adolescência. Ainda de acordo com a entrevista do site Amazonia, ele sempre morou perto de aldeias, justamente para não perder o contato com a cultura indígena. Ele ainda enfatiza que participou de todos os rituais xavantes, até porque se não o fizesse não seria considerado Xavante. Atualmente o jovem cursa Comunicação Organizacional na Universidade de Brasília (UnB).

Em $4^{\circ}$ lugar no ranking dos Youtubers indígenas brasileiros e com pouco mais de 19 mil seguidores, o canal Wariu desconstrói a visão de senso comum dos brasileiros sobre os povos indígenas por meio de vídeos explicativos.

Em 2017, o Ministério da Cultura lançou um edital para auxiliar produções audiovisuais de jovens vlogueiros em todo o Brasil. Cristian se inscreveu e apresentou um projeto para criar um canal sobre questões indígenas.

Desde que descobri o edital, fui me preparando. Eu não sabia editar, muito menos gravar, mas diante dessa oportunidade, me esforcei para aprender. Como eu sempre tive muita aptidão com meios tecnológicos, não tive tantas dificuldades" (LEMOS, 2018, online).

\footnotetext{
${ }^{15}$ Amazônia - Notícia e Informação. Disponível em http://amazonia.org.br/2018/12/pensam-que-deixode-ser-indigena-por-usar-smartphone-jovem-xavante-cria-canal-no-youtube-para-combater-preconceito/. Acesso em 11 de março de 2020.

${ }^{16}$ Idem 14
} 


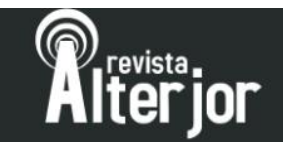

Após gravar o piloto, o jovem de 21 anos foi selecionado para receber a verba e produzir seu canal. Este piloto foi ao ar em 10 de agosto de 2017. Intitulado "As maiores dúvidas e mentiras que contam sobres os povos Indígenas EP.PILOTO”, o post obteve 12.597 mil visualizações e 308 comentários. Nele, o jovem indígena fala sobre algumas das dúvidas que mais costuma ouvir sobre a sua cultura. "Não aguento mais me perguntarem se ando pelado em casa ou na aldeia”, é a fala inicial do vídeo. Pouco depois, Cristian, que passou a vida morando na cidade e indo com frequência à aldeia, pontua. "Não, não ando pelado em casa. É muito constrangedor. Mas, na aldeia, vai depender da etnia, porque índio não é um povo só", esclarece Cristian.

O nome do canal "Wariu" é uma homenagem ao bisavô. Cristian faz o roteiro, gravação e edição dos vídeos. Além de um revisor ortográfico. Os recursos do edital são usados, principalmente, em aluguéis de equipamentos e no deslocamento quando faz gravações em áreas indígenas.

Dos 24 vídeos postados por Cristian, 10 são de cunho cultural, 10 político e 4 pessoal. Conforme podemos observar no Gráfico 5:

Gráfico 5: Conteúdos postados no YouTuber por Wairu Percentual de vídeos e conteúdos postados por Wariu no período de 2017 a 2020 - por tema

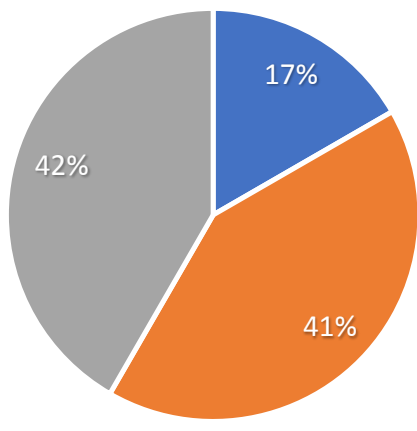




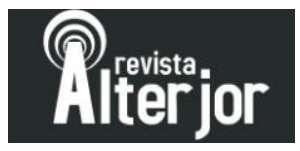

Em relação aos conteúdos postados desde sua criação, em 2017, até março de 2020, podemos observar a produção de material é baixa, conseguindo atingir somente em 2019 um vídeo por mês (vide gráfico 5).

Assim como em 2017, nos três primeiros meses de 2020 foi produzido apenas um vídeo. Os vídeos são longos e com a duração entre 5 a 10 minutos, bem produzidos, com trilha sonora e apresentação de créditos nas postagens.

O canal Wariu aborda etnias distintas e não apenas os Xavantes. Então os 10 vídeos que abordam o subtema cultura destacam-se: o que é ser índigena no Brasil; pinturas indígenas, literatura indígena. Cristian também visitou outras aldeias e entrevistou várias lideranças, como o vídeo intitulado "Como mantemos nossa cultura? com Alínor Aiakade Bakairi”, de 5 de setembro de 2018. Este vídeo obteve 5.919 mil visualizações e 52 comentários. Com 7 minutos de duração, o vídeo foi filmado na aldeia Pakera, no Mato Grosso, povo Kakairi. Os vídeos são legendados e sem erros de português.

A produção de Wariu relacionada a política, presente em $42 \%$ do seu conteúdo é voltado para um alinhamento de esquerda. Com críticas ao governo Bolsonaro como externado no vídeo "Primeira Marcha de Mulheres Indígenas", publicado em 18 de agosto de 2019. Com 1.811 visualizações e 15 comentários o vídeo traz como foco apresentar a primeira marcha de mulheres indígenas realizada em Brasília entre os dias 10 e 14 de agosto e o protesto dos povos indígenas do Brasil com o governo atual.

Os comentários são sempre de elogios ao canal e a escolhas dos temas dos vídeos são validados pelos seus seguidores. Ao todo são 175.676 mil visualizações e 2.067 mil comentários.

\section{CONSIDERAÇÕES FINAIS}

Dentre as estratégias de fortalecimento das identidades étnicas usadas nos dois canais dos Youtubers indígenas brasileiros abordados neste artigo, a divulgação da cultura dos povos originários e o combate a estereótipos e preconceitos tem bastante relevância, pois promovem produção de conhecimento, troca de saberes, formas e 


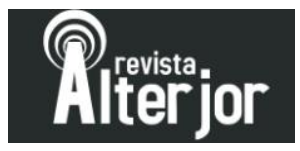

expressões da cultura indígena, denúncias, possibilitando que mais pessoas e instituições conheçam esta outra realidade e se mobilizem para possíveis resoluções dos problemas apresentados.

Percebe-se o caráter híbrido das identidades, pois ao mesmo tempo em que priorizam as temáticas culturais e aspectos tradicionais de suas etnias, os youtubers analisados atualizam a imagem do indígena contemporâneo a partir do uso da tecnologia, do vocabulário e da abordagem de temas cotidianos.

A comunicação praticada por Ysani e Wariu tem conseguido formular e pôr em prática estratégias de comunicação alternativas aos meios hegemônicos e têm alcançado resultados positivos, influenciando atores sociais em maior ou menor grau, haja vista a participação do público pelos comentários e até convites para participarem de debates, congressos e programas de TV. Nesse sentido, poderiam ser considerados midiativistas indígenas. Há uma ressalva, no entanto, no caso de Ysani pelo fato de estar alinhada à direita e apoiar o atual presidente do Brasil. Este é um aspecto paradoxal, visto que em diversos momentos o chefe do Executivo e sua equipe fizeram declarações preconceituosas e prejudiciais aos povos indígenas.

Por fim, pode-se reconhecer que, apesar do material de Ysani ter tecnicamente um caráter mais amador, o fato de haver postagens com maior periodicidade faz com que ela alcance maior visibilidade. Ao contrário de Cristian, que tem um conteúdo melhor trabalhado tecnicamente, porém sem volume de postagens ou periodicidade, o que contribui negativamente para sua visibilidade na rede.

\section{Referências bibliográficas}

ARAÚJO, W. F. ; FREITAS, E. C. (2012), “Quanto custa mudar o mundo?’ Análise da dimensão discursiva do ciberativismo na WikiLeaks", Fronteiras - Estudos Midiáticos, 14 (2), pp. 110-120. DOI: 10.4013/fem.2012.142.05.

BAUMAN, Zygmunt. Identidade: entrevista a Benedetto Vecchi. Rio de Janeiro: Jorge Zahar, 2005.

BRINGEL, B. e E. E. MUÑOZ (2010), "Dez anos de Seattle. O movimento 


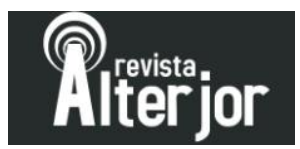

antiglobalização e a ação coletiva transnacional”, Ciências Sociais Unisinos, 46 (1), pp. 28-36. DOI: 10.4013/csu.2010.46.1.04.

BURGESS, Jean; GREEN, Joshua. YouTube e a revolução digital: Como o maior fenômeno da cultura participativa está transformando a mídia e a sociedade. São Paulo: Aleph, 2009. 239 p. Tradução Ricardo Giassetti.

BRAIGHI, Antônio Augusto. Midiativismo em análise: contribuições de uma pesquisa de doutorado. Revista Mídia e Cotidiano.Volume 12, Número 1, abril de 2018. p.42-59.

BRAIGHI, Antônio Augusto; CÂMARA, Marco Túlio. O que é Midiativismo? Uma proposta conceitual. In: BRAIGHI, Antônio Augusto; LESSA, Cláudio; CÂMARA, Marco Túlio (orgs.). Interfaces do Midiativismo: do conceito à prática. CEFET-MG: Belo Horizonte, 2018. p. 25-42.

CANEVACCI, Massimo. Autorrepresentação: movimentar epistemologias no contexto da cultura digital e da metrópole comunicacional. Revista Novos Olhares, v. 4, n.1, p. 16-20, 2015 Disponível em:

http://www.revistas.usp.br/novosolhares/article/view/102237. Acesso em: 28 abr. 2020.

CASTELLS, Manuel. Comunicación y poder. Ed. Alianza Editorial, 2009. 680 pág.

DI FELICE, Massimo. Net-ativismo. São Paulo: Editora Paulus, 2017.

EAGLETON, Terry. A idéia de Cultura. São Paulo: Editora Unesp, 2005.

LEMOS, Vinícius. Jovem Xavante cria canal no YouTube para combater

preconceito: 'Pensam que deixo de ser indígena por usar smartphone'. In BBC.

Disponível em https://www.bbc.com/portuguese/brasil-46427800. Acesso em $11 \mathrm{de}$ mar. De 2020.

MIX, Miguel Rojas. El imaginario. Civilización y cultura del siglo XXI. Buenos Aires: Prometeo Libros, 2006.

VEGH, Sandor. Classifying forms of online activism: the case of cyberprotests against the World Bank. In: MCCAUGHEY, M., AYERS, M.D. (ed.). Cyberactivism: online activism in theory and practice. London: Routledge, 2003.

SILVEIRA, Sérgio Amadeu. Ciberativismo, cultura hacker e o individualismo colaborativo. Disponível em http://www.revistas.usp.br/revusp/article/view/13811. Acesso em 28 de abr. 2020.

UGARTE, D. de (2008), O poder das redes: manual ilustrado para pessoas, organizações e empresas, chamadas a praticar o ciberativismo, Porto Alegre, EDIPUCRS. 